\title{
Problems of Russian construction education in an age of innovation: socio-cultural and legal aspects
}

\author{
Igor Pryadko ${ }^{1 *}$ and Igor 'Lebedev ${ }^{1}$ \\ ${ }^{1}$ Moscow State University of Civil Engineering, Yaroslavskoye sh. 26, Moscow, 129337, Russia
}

\begin{abstract}
In this paper we estimate changes of Russian higher education, aimed to incorporate In this paper we estimate changes of Russian higher education, aimed to incorporate the latter in the Bologna process. The analysis of the reforms is given in terms of need in training specialists of the construction industry. The article analyzes the conclusions reached on the issue by some teachers of Russian universities of civil engineering. Among the reasons for concern from the part of the Russian education community, it is called the low level of knowledge about the tasks of reforms and lack of information regarding measures to improve the education system. The investigation, in particular, points out that today the main issue of reforming is seen in creation of a single European intellectual space. At the same time, the questionnaire showed that the achievement of the stated purpose is prevented by the following factors: low level of student-builders in foreign languages and insufficient income. These circumstances make education abroad almost impossible for most students from Russia and reduce the competitiveness of graduates from Russian universities in labor market of the countries that joined to the Bologna system. The authors of the article pay special attention to the needs of executives of construction firms in qualified specialists. Most of the experts note the isolation of universities from solving problems of building practice, a noticeable lag of the national educational system from the western ones in training specialists in construction logistics and organization of construction sites.
\end{abstract}

\section{Introduction}

The purpose of this paper is to give an assessment to the impact that the principles of the Bologna agreement affect on the Russian system of higher education, and in particular on the training of specialists of the construction industry. The process of reforming the modern higher school as its main objectives proclaim the turn of educational institutions to the industrial sector, the maximum approximation of curricula for future professional activities. The construction industry is not an exception. Leading higher educational institutions of the country of construction profile are involved in the research activity on the background of the changes taking place. Scientific innovations are increasingly being intro-

*Corresponding author: Priadcko.igor2011@yandex.ru 
duced in the professional environment [1].A common place is that the emergence of innovative ideas and the use of advanced technologies are happening in the field of fundamental and exploratory researches. The search is currently underway and in educational institutions [2]. However, the University of civil engineering should not seek to replace a construction site. The authors write on the problems of modern construction education: S.A. Medvedev, M.A. Ivanova, L.V. Vlasenko, L.V. Makovsky, D.V. Polyakov et al., leaders of specialized universities expressed about that. The level of training of human capital in the construction industry in Russia, the graduates' readiness for innovative changes in the construction industry becomes the subject of periodic sociological studies. [3]. Special attention in publications is paid to issues of education of civil engineers in the aspect of sustainable construction [4].Their conclusions will be taken into account in this study.

Invention and introduction of new technologies in construction are beginning with the search at the level of fundamental theories in educational institution. And it is important in the national research centers, such as many universities, to create the conditions for innovation. The facts that we present below, demonstrate conclusively that the lead institution of civil engineering in the country in which we conducted our survey, - Moscow State University of Civil Engineering - fit in general into the picture of modern educational reforms.

Historians of education depicted the ideal in literature of the subject, - the university as a place where the community of teachers and the learners on equal terms conducts scientific researches. Intensive communication should be the learning method, the communication occurs primarily among learners. Now it is called the "subject-subject" interaction. That communication of two entities -a teacher and a student, is one of the fundamental principles of the university as a social institution, according to the concept of existentialist philosopher K. Jaspers. A joint study of the truth is the reason for the emergence of science as a form of social consciousness and the university as a social institution, aimed to distributetheculture and knowledge serving as an expression of the truth. The detailed scheme of the formation is represented in the treatise of K. Jaspers' "Idea of the University". German existentialist was convinced that the university as a social institution is essential for research, and explorative search is connected with the selfless pursuit of the truth by its content and purpose. This is possible only in conditions of the dialogue on equal footing of students and faculty. The autonomy of the university maintains a high level of democracy. The education during the courses has Socratic, i.e. interactive character [5].

Currently, the turn to fundamental research is not accidental in national institutions of higher education of construction profile. However, there is an ambiguous attitude how the reform is carrying out among the students and teachers of MGSU, as well as other high schools of Moscow and Moscow region. Hence the task that is put in the article: to answer the question, what is the reason that the Bologna process has not become popular among students and teachers.

There is the perception among researchers that Bologna process itself is nothing but a unification and adaptation of the Russian education system under the western one, primarily at the expense of Russian educational institutions, and not by all the participants of this process in the country implementing such a system of education. It is indicated the benefits that are received participants of this process in the literature of the subject. The question arises: What are the advantages of acquiring Russian students, what specifically expressed their preferences? Are there advantages from the introduction of the Bologna system, really? Finally, we should find out how much guaranteed of employment of a graduate with Bachelor's degree in the countries-participants of the Bologna process. And how much guaranteed further education in magistracy in their country of residence? On the authors' opinion, these guarantees should not only be formally secured, but also put into practice with concrete examples, confirming the quality of the process itself. 


\section{Experimental section}

The authors have adopted the method of historicism in the experimental part of the study, the method involving the analysis of the processes in education system in their formation, dynamics and relationships. It is proposed to consider the range of sources which are attracted by the authors to analyze the history of modern Russian construction education.

The authors of the article do their conclusions on the basis of media data and the poll. The survey was conducted among learners and teachers of the profile institution and the Faculty of Design, which trains specialists in the organization of urban environment. What is the essence of the problem, which was solved by traditional method for sociology, - collecting empirical data? The survey conducted by the authors concerned the relationship to the changes taking place in universities. The authors sought to determine the level of awareness of the reforms under the Bologna process. The respondents, as mentioned, were students and teachers of educational institutions of the Moscow region. Students and teachers of the Faculty of Design of the International Slavic Institute, of the ISA and EUIS institutes of NIU "MGSU", RGSU (Naro-Fominsk branch) were interviewed. The students learned on the specialty "Environmental design", "Architecture", "Industrial and civil engineering". It was carried out a comparative analysis of the views of students and teaching staff, based on the survey.

According to the literature of the subject, the main aim of the Bologna process at the present time is seen in the creation of the single European intellectual space. The latter is to facilitate education, including in Old World. However, just at this point, the survey has revealed the problem: the low level of English knowledge of construction students (as rated by their knowledge of $65 \%$ respondents) and the low level of income ( $80 \%$ respondents). But the number of those who have sufficient language training in their subjective opinion to study at a foreign university, is up to $35 \%$. On this basis, we can assume: well-educated young people who know foreign language are not still quite a lot in the middle and lower classes of society.

In addition to polling method the authors have adopted the analysis of sources on the history of modern construction education.

\section{Results section}

At present, it is stressed that the involvement of educational institutions of the Russian Federation in western research and pedagogical discourse makes it possible to overcome the obstacles in their dynamics and increase the mobility of all actors involved in educational activities [6].Just the creation of a common intellectual space is seen as the main task of the reforms of education institute in the Russian Federation [7]. The problem is worthy, of course. But the single space for the exchange of scientific ideas can be useful only in the case when these ideas are available. It is not always restrictions of intellectual freedom coming from the supreme power (as they were pretty hard during the Soviet period) appeared as critical for braking science. We note that in our country, even in the Soviet period, such ideas were available. Here are two illustrative examples from the exact sciences. Mathematician and logician Zinov'ev, popular in modern Russia, was seen by Mr. Henrik von Wright (1916-2003). This historian of science had a pan-European renown, approved the search in the field of applied researches of logical semantics, undertaken by Russian researcher. Now is the second example. The first works on Gottlob Frege, prof. B.V.Biryukov, died in 2013, as well as Zinov'ev was a disciple and follower of Sophia Alexandrovna Janowska, were marked by the authoritative Swiss specialist in the field of mathematical logic I.Bohensky.Despite the "iron curtain" the first work of Russian logic the book of Boris Vladimirovich about Frege in 1965.The book was translated into English 
and published by the Dordrecht publishing house ([8], it [9]).And later in the Soviet era B.V. Biryukov regularly participated in "Frege's readings" held in Germany, Bremen (1999), in Erlangen (1995) in Jena (1979). Even in the most difficult for Russian science the 30-thof XX century, the delegations of scientists from Polish, German, Italy visited the Soviet Union regularly. There was exchange of ideas, research experience.

Let's turn to the area of construction sciences. In these application profiles, such as structural mechanics and soil mechanics, there was no braking. It is enriched the theory, implemented bold engineering and architectural projects. It was opening organizations of research focus (e.g., The Institute of Foundations and Underground. Facilities, led by N.M. Gersevanov (more on that explorer .: see [10])). T.M. Stoll offered their technological works in the 60-ies of XX century at the Department of "Organization of construction" MISI (Moscow Civil Engineering Institute) [11]. And the list goes on. Even today MGSU has strong ties with Germany, with the countries of the Near and Far East [12].

According to the regulations adopted by the EU authorities, the education reform has the following objectives: the organization of a two-tier system of training, the first step when it lasts for more than 3 years, and the second is to lead to a master's degree or doctorate. It is provided the creation of a special annex to the diploma, it is necessary to form the comparison criteria of educational degrees; to introduce a standardized record system, which allows producing "re-record" at all open intellectual space and a number of others actions (see. [13]).

In recent years, the Russian institutions of higher education commit themselves to the Bologna system and move to the two-tier system of education. In this case the objectives pursued by the process itself, is not always clear to the participants that in many respects difficult to transition to the new educational standards. The teaching staff of the "old school" as the executives, afraid of sudden and quick changes in education, and their fears are grounded. The final decision on the reform of educational institutions in accordance with the Bologna standards, makes the Ministry of Education and Science of the Russian Federation. Someone concludes that certain problems arise from the lack of reliable information on the goals and objectives set by the participants of such a complex, yet important matter of reforming the national education system. Now very few people deny the necessity of entering Russian higher education in the world educational process. That is why the leadership of higher education institutions faces the task of competent and possible "painless" transition to the new system.

Let's return to the outcome of the survey conducted. A significant proportion of students $(85 \%)$ cannot give the definition of "record unit" and even more Bolognese phrase "education loan". Really, this result proves the fact that the information about the content of the curricula was not communicated to students. Based on the curriculum content the classes are held and knowledge in the disciplines of the curriculum is assessed. In addition, the majority of respondents $(86 \%)$ did not have any information about the possibility to take a course of choice, according to the Bologna documents, not to study a course as such. We add here that it does not specify the parameters of assessment and acquired skills of such education. But in some cases the assessment will be missing or grading "unsatisfactory" by the end of the learning course. Data processing of the survey confirmed the hypothesis already expressed by the authors that a significant proportion of students are poorly informed about the study load and the criteria for the final assessment of knowledge. But the lack of information makes it difficult to interact both between the initiators of "Bologna" reforms and staff of universities, and among the inventors of new technologies and building designers (conclusion of V. Sukachenko, head of Vinzilinsky plant of expanded clay, made him on the conference of leaders of construction companies). In other words, the contradictions chain extends beyond higher school. 
Managers of construction companies associated his hopes with higher school reform [14]. The article of I.P. Pryadko and L.V. Vlasenko devoted to this issue, in particular, emphasized: "Leaders of the construction firms linked the competence of the staff to the flexibility of thinking, the ability to switch to other spheres of activity. The depth of the preparation is not associated with the narrow and dogmatic thinking. Just today, it becomes important because we live in an age of unprecedented acceleration of scientific and technological progress, and the latter inevitably affects the construction sphere"[15].

Managers of construction companies are direct consumers of final products of universities,- trained specialists by hicher school- see the solution in the introduction to scientific research the competitive elements. N.Myasnikov(head of the company "Warm House") proposed a mechanism to promote innovation in the construction of apartment buildingsat the round table in Tyumen. He recalled, in particular, that in many countries "the state is the customer of prototypes, dozens of homes are being built, which compete with each other. Potential customers can compare in practice, what is more profitable to use". Similar polygons of construction profile can be created on the basis of research construction institute, where the potential customer could count on expert advice. As well as representatives of universities, developers and architects rely on power, convinced that its intervention arranges a dialogue between science and industry. Categorically view of expert A. Tabanakov is: "If the authorities do not have the task to implement high-tech, panelist says, nothing will" [16].It is important that the representatives of architectural and building schools took part in the discussion of the problem of application of innovation in construction. This has happened in the round table, organized by edition of "Technology and organization of construction industry». Curious suggestions made at the event by professor M.N. Ershov from the Department "Technology and organization of construction industry of NIU "MGSU" and by vice-rector for scientific and industrial activity of the same university $M$. E.Leibman. Panelists noted a noticeable lag of the construction education in Russia. It can be concluded based on the results of the discussion about the need to learn foreign experience in Russia. But despite the complaints of teachers, the transformation taking place in the sphere of preparation of construction workers. The system of training and project activities are widely introduced innovations [17]. The exposure of NIU "MGSU" at the VI AllRussian Innovation Forum NAUKA0+ is a positive example. Here, the modular layout of the exploited "green" roof was presented. While it was only a mock-up. But perhaps in the future, one of the roofs of the University of civil engineering will be decorated with a prototype. What are the proposals of young researchers? The inventive design protects of the roof from destruction under aggressive environmental exposure [18]. The main objective of such events is the popularization of applied researches, involvement in innovative search of young generation of scientists. It is gratifying that the University of civil engineering takes an active part in it.

The authors of this article believe that the "competence approach" of preparation of construction specialists does not solve, and to some extent exacerbated the approach, that was made by one of the elements of the Bologna process in Russian education. Indeed, in this case, the thoroughness of preparation and learning of the laws of thought, are superseded some common but superficial erudition, breadth of knowledge, with a lack of indepth knowledge in a particular industry or in the construction profile. Professional community, leaders of construction companies put the question squarely about preparing thoughtful and qualified construction staff, be able to professional and adequate approach to the process of designing and constructing buildings.

Let us now to analyze the law side of the Bologna process. We have made the analysis of the concept of "bachelor", as reflected in the regulations, being limited to article format.

The preamble of the Order of the Ministry of Education of the Russian Federation №201 from March 12, 2015 is "item 159 changes made in the federal state educational 
standards of higher professional education in the education profiles, verifiable qualification (degree) "Bachelor "'[19].This formulation, as the qualification "Bachelor" has not yet been filled with concrete substance and can cause a lot of questions from a prospective employer to an applicant. And in fact, as explained by leader who are these "bachelors in construction" and what are the requirements for them to be applied, for example, on such criteria as the special assessment of labor? That is why the award of a graduate degree "specialist" or "engineer" more understandable to the employer, rather than "bachelor" or "master". Information content of the latter term is currently understood only civil servants from Ministry of education within the Bologna process.

The educational system of Specialty GOS VPO meant the preparation of the future builder of certain specialty in the forms of learning: full-time -5 years and part-time -6 years, which made it possible to award (assign) qualification in the specialty. Bologna system of education "Bachelor" does not focus specifically on the acquisition by a student of certain specialty in the future, so professionalism is eroded.

The essence of the baccalaureate is the maintenance of the system features of the Bologna process, Russian high school is connected to the system by the Ministry without an extensive discussion this issue not only by the teaching staff but also parents of students (applicants). A natural question arises: the 2-year magistracy is able to give knowledge and to prepare a specialist required by a labor market that existed at the specialty? Of course, the buyer on the labor market does not clear the essence of "indefinite under-specialist by education level "Bachelor", and his professional suitability as a young professional. Although the innovativeness is also required from a specialist in the development of projects.

It should be noted here that in the transition to a two-tier system of education, bachelor and master, methods of teaching technical and humanitarian disciplines are different in content of lectures and practical lessons, based on the educational competencies.

Of course, the process of involvement of Russian higher education in the Bologna process is lively discussing. It is because it is worth noting that to this day joining the national high school to the Bologna system is discussed by representatives of the scientific community, the leaders of different political parties, as evidenced by the growth of critical articles and papers about the reforms taking place both here and abroad. The representatives of the scientific and academic community of the European Union actively criticize the reforms. Here is a bitter prediction placed in the German newspaper «Zueddeutsche Zeitung». It is painted publicist: "Bologna! - Addresses the author is not so much to the city as to the leaders of the European Union, took vital decision for European education, - it is magnificent city, where many of the proud tower debating with one another as to which of them is more beautiful, as this city could become a symbol of a bulldozer, which levels the variety of subjects and methods of teaching throughout our territory? "[20].Such predictions about the outcomes of the reform were expressed in 2004, by the German pedagogue W. Essbach.

Carrying out the reforms of national high school, we need to take into account not only overseas developments, but also innovative educational ideas worked out in the space of Russian philosophical and pedagogical thought. It should also be recalled about these ideas in the discussion section of the paper. We restrict ourselves to the conclusion reached by P.A. Florensky, he is an outstanding scientist, philosopher and priest, in the article "Anticipated polity in the future". The thinker was convinced: in the future secondary and high schools should give not so much the amount of knowledge, but to acquaint with the methods of their obtaining. This thesis can be seen as a demand of competence approach, which prevailed in our education only in the second decade of the XXI century. But back to the conclusions of Florensky. Factual material of disciplines are not self-sufficient and it is necessary an illustrative material for the use of a specific set of cognitive techniques. Paul was convinced:"Education should be based on the principle "not much, but a lot of". Learners should try to master the cognitive techniques, precision of thought, taste bringing know- 
ledge to the end, intelligibility of taste ". And then, from the humanities, the Russian scientist considers the main features of the content of the course, both in secondary and in a high school. At the initial stage of the educational process it is necessary to "teach the rudiments of mathematics, [basis] of Mathematical Sciences [including logic] and the natural sciences". And then, Florensky proposes to abandon the standardization and unification of educational plans as opposed to the Bologna "reformers" of XXI century: "The unity of the school should be rejected, on the contrary, may be a variety of types of programs and ways of learning ...". Carrying out reforms of higher education in the moment, we take into account the discussion ideas of the Russian scientist of the beginning of the last century.

\section{Conclusions}

The priority of Russian universities is reorient, change the nature of the ongoing reforms at the moment in favor of developing national science and education, as it is largely undertaken in the already mentioned NIU "MGSU" within the project Tempus, on the Department of Social, Psychological and Juristic Communications. The objective of the project is to update educational plans for preparing specialists in the area of civil engineering in higher educational institutions of the Russian Federation, and some post-Soviet countries in accordance with the requirements of the Bologna documents in order to expand the range of opportunities for modernization. We will return to this in future works.

The authors believe that the measures provided in terms of the TEMPUS project, in a certain sense, to "reconcile" the tower of the ancient Italian city.

\section{References}

1. A.D. Ishkov, M.Y. Mishlanova, K.P. Grabovyi, Intern. Journal of Appl. Engineer, 3(11) (2016)

2. M.G. Leontev, MATEC, 73 (2016)

3. Z.I. Ivanova, O.V. Yudenkova, Middle-East Journal of Scientific Research, 16 (8) (2013)

4. Z.I. Ivanova, O.V. Yudenkova, Asian Social Science, 11(1) (2015)

5. K. Jaspers, Die Idee der Universitaet (Berl, Springer-Verlag, 1946)

6. S.A. Medvedev, The Bologna Process. Russia and Globalization, the Bologna Process and its Implications for Russia (RETSEP, Moscow, 2005)

7. V. N. Chistokhvalov, C. U. Kim, A.V. Omurzakova, Accreditation in Education (Yoshkar-Ola:Accreditation in Education, 2013)

8. B. Birjukov, Two Soviet Studies on Frege (Dortrecht: Redel, 1964)

9. I.P. Pryadko, Historical and Philosoph. Yearbook. 1 (2013)

10. N.M. Gersevanov, Fundamentals of Soil Mass Dynamics (ONTI, Moskow, 1937)

11. At the Root of the Practical Sciences, Construction personne, 9, 9-10 (2016)

12. N. Ovchinnikova, Construct. 09,1664, (2016)

13. M.A. Ivanova, Proceedings of the XVII International Interuniversity scientific and practical conference (2014)

14. N.G. Miloradova, A.D. Ishkov, MATEC , 73 (2016)

15. L.V. Vlasenko, I.P. Pryadko, Integration, partnership, and innovation in construction science and education, 1, ( 2012)

16. T. Vorob'eva, Tyumen' business jour, 8, 130 (2013) 
17. E. Romanova, Materials Science Forum, 871, 132 (2016)

18. Flash to innovation, Construction personne , 8, (2016)

19. URL: http://fgosvo.ru/uploadfiles/fgosvob/080301.pdf

20. W. Essbach, Mit dem Buldozer gegen die Universitaet (Zued, 2004) 